\title{
Model course to revalidate deck officers' competences using simulators
}

\author{
Marcel·la Castells ${ }^{1} \cdot$ Santiago Ordás $^{1} \cdot$ Clàudia Barahona $^{1}$. \\ Jordi Moncunill $^{1}$ - Cees Muyskens ${ }^{2}$ - Wibbo Hofman ${ }^{2}$. \\ Stephen Cross $^{2}$ - A. Kondratiev ${ }^{3}$ - A. Boran-Keshishyan ${ }^{3}$. \\ A. Popov $^{3}$-S. Skorokhodov ${ }^{3}$
}

Received: 14 October 2014 / Accepted: 10 September 2015

(C) World Maritime University 2015

\begin{abstract}
In accordance with Part A, Chapter I, Section I/11 Revalidation of Certificates of the Standards of Training, Certification and Watchkeeping for Seafarers (STCW) 2010 Convention, continued evaluation of professional competence shall be established, among others, by successfully completing an approved training course or courses. Every master, officer and radio operator holding a certificate issued or recognised under any chapter of the convention other than chapter VI, who is serving at sea or intends to return to sea after a period ashore, shall be required, at intervals not exceeding 5 years, to demonstrate continued professional competence, in order to continue to qualify for seagoing service. The main objective of this research is to design a model course using simulation technology to train and demonstrate seafarers' competence in accordance with the provisions of STCW Code for existing seafarers who need to revalidate their professional maritime certificates also in accordance with the standards governing the use of simulators, Reg I/12 of 2010 STCW Code. The purpose of this revalidation simulation-based model course is to assist maritime training institutes and their teaching staff in organising and introducing specific training courses for revalidation of certificates of competence ( $\mathrm{CoCs}$ ) as well as enhancing, updating or supplementing existing training material where the quality and effectiveness of the training courses may thereby be improved. Only those STCW competences relating to
\end{abstract}

Marcel·la Castells

mcastells@cen.upc.edu

1 Barcelona School of Nautical Studies, Universitat Politècnica de Catalunya, BarcelonaTech, Barcelona, Spain

2 Maritime Institute Willem Barentsz, NHL University of Applied Sciences, Leeuwarden, The Netherlands

3 Admiral Ushakov Maritime State University, Novorossiysk, Russian Federation 
ship bridge simulators will be considered for the model course scenario development and testing.

Keywords Maritime education and training - Simulation -STCW Code $\cdot$ Revalidation of certificates

\section{Introduction}

International Maritime Organization (IMO)'s International Convention on Standards of Training, Certification and Watchkeeping for Seafarers (STCW) (IMO 2011) was ratified by all maritime nations. Today, IMO has advised/encouraged all contracting governments/interested parties to review and, as necessary, to revise their crew's academic/vocational competency described in STCW. Furthermore, the European Maritime Safety Agency (EMSA) started a regular assessment process in order to improve the quality of maritime education and training (MET) institutions throughout EU members, candidate countries and others.

In accordance with Part A, Chapter I, Section I/11 Revalidation of Certificates of the STCW Code, continued professional competence shall be established, among others, after successfully completing an approved training course or courses. Every master, officer and radio operator holding a certificate issued or recognised under any chapter of the Convention other than chapter VI, who is serving at sea or intends to return to sea after a period ashore, shall be required, at intervals not exceeding 5 years, to demonstrate continued professional competence in order to continue to qualify for seagoing service.

This paper proposes two model courses using simulation technology to train and demonstrate seafarers' competence in accordance with the provisions of the STCW Code for existing master mariners who need to revalidate their professional maritime certificates also in accordance with the standards governing the use of simulators, Reg I/12 of the 2010 STCW Code. The purpose of these revalidation simulation-based model courses is to assist maritime training institutes and their teaching staff in organising and introducing specific training courses for revalidating certificates of competence (CoCs) as well as enhancing, updating or supplementing existing training material where the quality and effectiveness of the training courses may thereby be improved. Only those STCW competences relating to ship bridge simulators will be considered for the model course scenario development and testing.

\section{Main scope and methodology}

The two model courses proposed were developed thanks to the International Association of Maritime Universities (IAMU) Research Project entitled "Simulationbased model course to demonstrate seafarers' competence for deck officers' discipline". The project was divided into different stages, which were assigned to the three different participating universities: Barcelona School of Nautical Studies (Universitat Politècnica de Catalunya, Spain) leading the project, Maritime Institute Willem Barentz (University of Applied Sciences, The Netherlands) and Admiral Ushakov Maritime State 
University (Russian Federation). Each partner led different workpackages corresponding to each of the stages of the project. Meetings at the different institutions together with some videoconferences were held regularly to help the partners make decisions concerning the scope and progress of the project and to agree on aspects of the course design and methodology.

The working process followed included several main steps. First of all, we studied the state-of-the-art use of the simulators in $\mathrm{CoC}$ courses and the assessment of national and international regulations concerning $\mathrm{CoC}$ courses. After analysing the results, we saw that there was a need to harmonise the aforementioned courses, which confirmed our initial project hypothesis. Secondly, in accordance with the spirit of STCW which promotes the use of simulators in maritime education and training since 1995, we analysed the use of simulation technology. This is an important issue, considering that, nowadays, the competences of seafarers are usually demonstrated only in oral or written exams. Having identified the main aspects concerning the use of maritime simulation for the training and assessment of seafarers, we decided to take the inventory of the competences that could be demonstrated by approved simulator training, according to part A of STCW 95/2010 Code competence tables. We found that 26 competences out of all the ones described in column 1 of Tables A-II/ 1 and A-II/2 of STCW may be evaluated using a simulator. Nevertheless, not all knowledge of each competence, as described in column 2 of Tables A-II/1 and A-II/2, is assessable using a simulator, so it was necessary to further analyse which skills required the use of additional material.

Taking into account the results obtained from this initial analysis, namely the lack of harmonisation of $\mathrm{CoC}$ courses together with the need to incorporate simulation technology in MET, we decided to design a course which meets the new requirements of the STCW and provides schools and maritime authorities with a modern way to examine the revalidation of the expired CoCs. The design was based on an IMO model course structure as we considered this as the best option if the IMO adopts this course for revalidating the professional certificates at international level in the future. In addition, we incorporated methodologies from course design research materials in order to design a didactic tool that would be suitable for maritime training institutions (Cross 1993, 1996; Dubin and Olshtain 1986; Barahona and Hernández 1999).

Once the revalidation simulation-based model course was designed, a course book with schedules, simulator lessons and competences trained by simulation was delivered. The publication presented provides the model contents to demonstrate maritime certification competence (de Catalunya UPC 2014). In addition, a full set of documented simulator scenarios was incorporated into IAMU's e-learning platform for maritime instructors, which was a valuable and useful work often missing in most maritime academies (http://iamu-edu.org/moodle/).

\section{Current national refresher courses}

In order to analyse the current situation of refresher courses, basic research to identify current national refresher and update programme courses was carried out. 
To obtain this information, a questionnaire was sent to all IAMU members with 14 questions.

From the questionnaire, we obtained 22 answers (39\% of the IAMU memberships). Three of the 22 institutions surveyed do not have a revalidation programme for $\mathrm{CoC}$.

From the answers received, the following figures (see Figs. 1, 2, 3 and 4) and main results were obtained:

As can be seen in Fig. 1, almost all institutions assess both courses, deck and engine officers and none of them assess only the engine officers' discipline.

From Fig. 2, we can observe that there are some differences concerning the kind of topics that the revalidation courses assess.

From the 19 institutions analysed, 17 use simulators in the $\mathrm{CoC}$ revalidation course and 8 of them use all types of simulator (see Table 1).

Considering the time devoted to simulation in the revalidation courses analysed, Fig. 3 shows that more than $75 \%$ of the institutions use simulation on the revalidation course between 25 and $50 \%$ of the time.

Also, course duration varies considerably from country to country (see Fig. 4) as it depends on government requirements, the kind of basic education received and the requirements regarding the duration of the sea stage.

On the basis of the performed research, we can say that the majority of countries began implementing $\mathrm{CoC}$ revalidation programmes for the training of maritime officers, using navigational simulators, Global Maritime Distress and Safety System (GMDSS) simulators, cargo handling simulators and engine room simulators during the educational process.

However, answers vary considerably from country to country and there is no harmonisation concerning revalidation courses. In the light of the fact that the STCW 1978 Convention has been amended by the 2010 Manila Amendments and contains new requirements for all seafarers, those revalidating their certificates of competency will be required to submit additional evidence to ensure that their certificate is valid for service on certain types of ships after 31 December 2016.

The development of a simulation model course for revalidation of $\mathrm{CoC}$ will provide the required education level and homogenise the approaches of different countries concerning revalidation programmes.

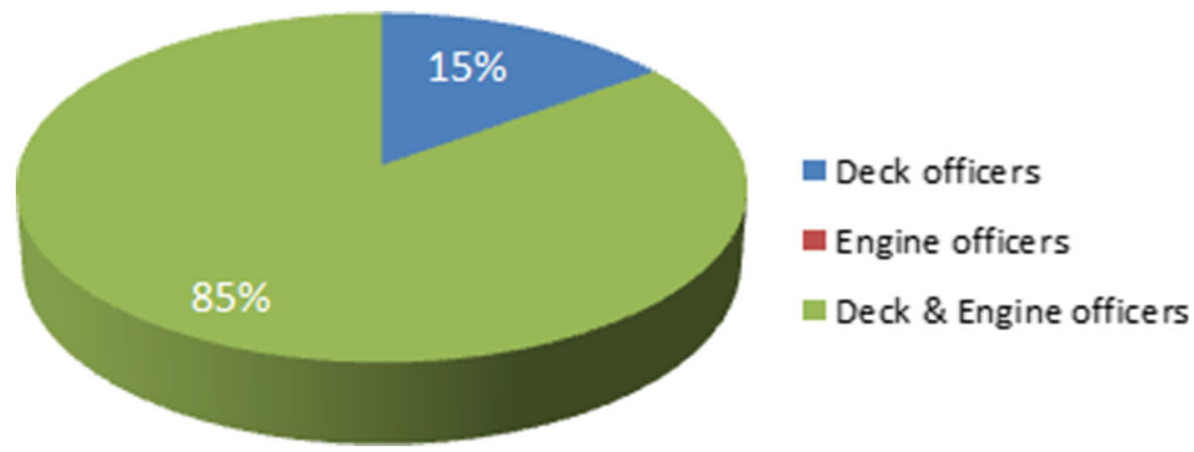

Fig. 1 Question 1: Which kind of course do you assess? 


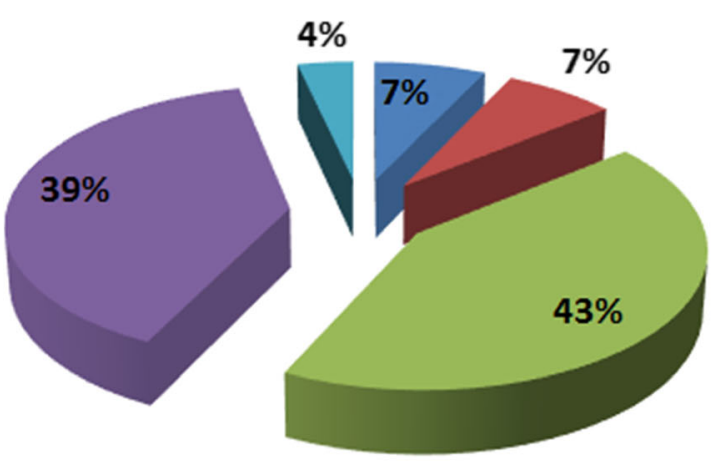

Fig. 2 Question 2: Which kind of topics do you assess? New regulation for
operational level

new regulation for management level

All STCW competences for operational level

all STCW competences for management level

Other

\section{Study of the application of simulation technology}

Simulation is a realistic imitation in real time of any ship system, for example ship handling, radar and navigation, propulsion and cargo/ballast, incorporating an interface suitable for interactive use by the trainee or candidate either within or outside the operating environment and complying with the performance standards prescribed in the relevant parts of this section of the STCW Code.

Within IMO, an Intersessional Simulator Working Group (ISWG) was established in order to organise and structure simulator-related matters for inclusion in the STCW revision. One definition adopted by the ISWG (IMO 1994) reads: "Simulation is a realistic imitation, in real time, of any ship handling, radar and navigation, propulsion, cargo/ballast or other ship-system incorporating an interface suitable for interactive use by the trainee or candidate either within or outside of the operating environment, and complying with the performance standards prescribed in the relevant parts of this section of the STCW code". More definitions and classifications related to simulation can be found in the industry (DNV and Det Norske 1996; IMSF 1994; INSLC 1990).

There are some previous studies related to simulator studies (Bjorklund et al. 1987; Boer 1991; Daggett 1994; DGSM et al. 1994; IMO 1996; Kayten et al. 1982; McCallum 1996; MSA 1995; Muirhead 1988; Tonsberg Maritime et al. 1987).

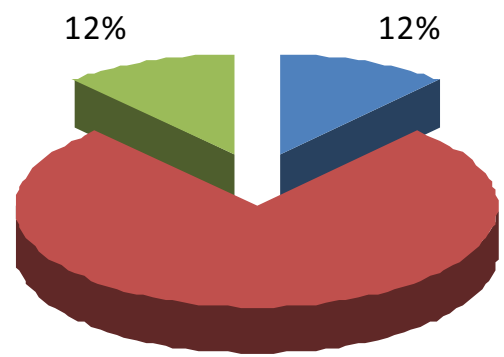

$76 \%$
Less than $25 \%$ of the time

Between $25 \%-50 \%$ of the time

Between $50 \%-75 \%$ of the time

Fig. 3 Question 3: How much time do you devote to the use of simulators on the revalidation course? 


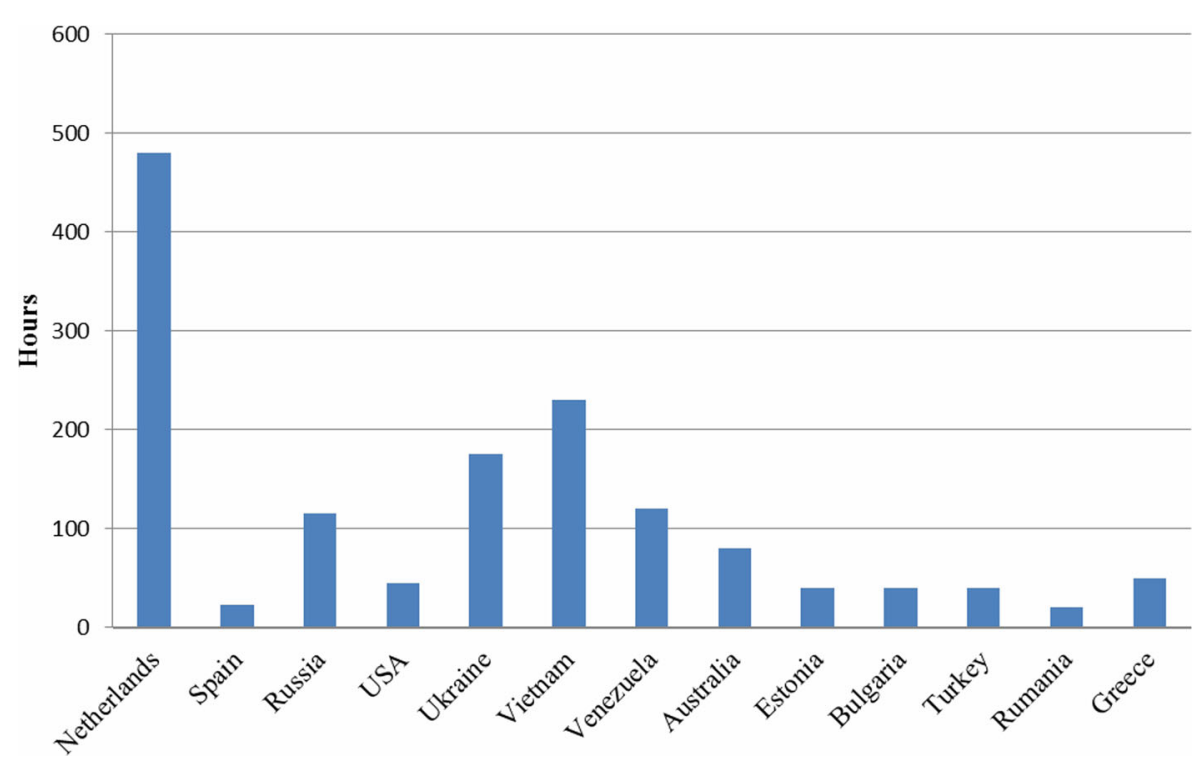

Fig. 4 Question 4: What is the duration of the course?

This section identifies the characteristics of maritime simulators (types and classification), simulator training and general conditions of the simulator training. At the end of this section, an analysis of which maritime competences can be assessed using simulation technology according to chapter II, part A of the STCW 95/2010 Code is carried out.

\subsection{Types of maritime simulators}

The fact that a simulation system represents a powerful teaching tool, which can lead to more effective training outcomes as well as to a more efficient use of the teaching time available, adds to the increased popularity of simulation equipment. Additionally, the assessment of seafaring skills and competences can be performed in a life-like simulation centre, which resembles as closely as possible the real system called 'ship'. As IMO sees the necessity to assess competence rather than knowledge in order to improve shipping safety and as simulators offer possibilities for meeting this need, it seems,

Table 1 Type of simulator used by institutions

Type

Navigational simulator

GMDSS simulator 
without doubt, that much more emphasis will be placed on marine simulation in the years to come.

The radar and ship handling simulators are the most well known and widespread, but it is quite surprising to see which other types of activities and equipment have become models for a maritime training simulator system and, up to date, have been developed and installed:

- Navigation equipment trainer (NAV)

- Communication procedures/GMDSS equipment trainer (COM)

- Radar simulator (RAD)

- Radar and navigation simulator (NAV/RAD)

- Ship handling simulator with/without motion platform/image generation (SHIP)

- Fisheries simulator

- Inland waterways simulator

- Dynamic positioning simulator

- Crane handling simulator (CRA)

- Vessel traffic management simulator (VTS)

- Search and rescue management trainer (SAR)

- Oil spill management trainer (SPILL)

- Propulsion plant trainer

- Steam generation plant trainer

- Electrical power plant trainer

- Refrigeration plant trainer

- Cargo handling trainer (CAR)

- Ballast control trainer (BAL)

- Dredging ship trainer

- Offshore process simulator

- Drilling technology simulator

Note that names in parentheses are assigned to refer to each particular type of simulator later on.

This list is not intended to be all inclusive. As technology advances, new systems, both from the shipping industry as well as within the simulation techniques, are being created with certain regularity.

\subsection{Types of simulator training}

A simulator is a training tool, which has to be integrated into a global training programme. This means that a simulator can and should be used for the training of normal and emergency situations. This is possible without endangering people or the environment, even if the training actions are not performed properly. Once the quality of the training efforts has been assured as indicated above, it will become necessary to distinguish the type of training that is to be performed, especially related to the seafaring profession. The training can be done in different modes and at various levels. If the training programme is of a modular design, the specific training requirements can be matched with each module. 
Investigation into the design of training scenarios will offer a possible division of training into five basic types described as follows:

- Team training: A team is a group in which decisions are made based on evaluation of information in order to execute the necessary operation. Team training is carried out to establish or to improve a team as a means to lead to decision training.

- Operator training: Operator training is required in order to train a person concerning proper equipment operation procedures. Ships are fitted with equipment suitable for such training so operator training is highly relevant in the maritime profession.

- Decision-making training: Decision-making training is done in order to train persons in making the right decisions. After evaluating a given situation, they should carry out the necessary action to reach a defined goal. In many situations, the decision-maker can communicate directly with the equipment rather than through an operator. Thus, the decision-maker becomes an operator.

- Procedure training: Procedure training takes place when training a group of persons in the correct execution of a specific procedure.

- Maintenance training: This is done in order to train individuals in either technical or condition control maintenance.

Without proper identification of the type of training which is to be performed, it will be more difficult to reach a quality composition of the training, in general, or training by means of simulators, in particular.

\subsection{Assessment of simulator training}

It is a common practice that all training and educational efforts will include a stage of assessment and evaluation to monitor if the training objectives have been met. Over the years, various systems for evaluation of education and training have been developed and applied. Usually, every teaching or training institution will be involved in evaluation and assessment. However, to what extent and by which methods are aspects which have been discussed by educationalists in the past and will continue to be open for discussion (Rowntree 1987). With the revised STCW 95 Code, the evaluation of skills has been indicated within the assessment of competences, which presently constitutes a major effort of the maritime training establishments.

The method used to assess will depend on the training tool applied. Furthermore, the actual skill, which is supposed to be acquired and which should be evaluated, will differ and range from very elementary, like making a certain knot, to very complex, like piloting a vessel. In competence-based training, the evaluation can preferably be done with or on the training tool that has been used. In the case of acquiring complex skills, this could mean on board a vessel or with the tool, which was used to represent the vessel, such as a simulator.

Although not done in a universally structured manner as with the assessment of other training systems, some attempts are being made by training providers to assess 
the trainee performance and, thus, effectiveness of simulator training. An overview of the methods presently used is given hereafter:

- Checklists: One of the most common methods used in the assessment or evaluation of practical training.

- Plots and printouts: Either independently or together with checklists or other means, a commonly used method for evaluating student performance on a (bridge) simulator is by means of a plot of the sailed track or a printout of any relevant parameters monitored during the exercise.

- Examiner evaluation: The easiest method by far is the observation of the trainee by the instructor/examiner who then subjectively evaluates his/her performance.

\subsection{Listed competences, chapter II, assessable using a simulator}

It is of interest to make the inventory of which competences can be demonstrated by approved simulator training, according to part A of STCW 95/2010 Code competence tables. In the $\mathrm{CoC}$ revalidation model course structure, these are the competences that will no longer require theoretical, written or oral examinations but can be practically demonstrated by means of simulation. Only those competences concerning ship bridge simulators will be considered for the model course scenario development and testing. That is, a simulator is used to simulate equipment that can be found on board, taking into account the impact of external events, but it is not conceived to simulate external phenomena alone.

There are a total of 39 competences described in column 1 of Tables A-II/1 and A-II/2 of the STCW 95/2010 Code, and 26 may be evaluated using a simulator, that is the $66.7 \%$. There are a total of 19 competences for the operational level, and 11 of them can be evaluated using a simulator (57.9\%); there are a total of 20 competences for the management level, and 15 of them may be evaluated using a simulator (75\%).

The legal basis for evaluating only with a simulator is found in column 3 of the tables provided (see Fig. 5), where it says that for all these cases: "Examination and assessment of evidence obtained from one or more of the following competences: (...)". In all cases, one of the modalities is approved simulator training, where appropriate.

\subsection{Knowledge, understanding and proficiency of column 2 of Tables A-II/1 and $\mathrm{A}-\mathrm{II} / 2$}

In column 1 of Tables A-II/1 and A-II/2, the competences to remember (or update) and assess are mentioned, but in column 2, the knowledge to acquire is specified. Therefore, of the 26 competences evaluable with a simulator, not all knowledge of each of these competences is assessable using a simulator but may require the use of additional material.

A more detailed selection will be provided based on the specific knowledge that students need to refresh or update and, for which, they must demonstrate their understanding and proficiency. 
Table A-II/1

Specification of minimum standard of competence for officers in charge of a navigational watch on ships of $\mathbf{5 0 0}$ gross tonnage or more

Function: Navigation at the operational level

\begin{tabular}{|c|c|c|c|}
\hline Column 1 & Column 2 & Column 3 & Column 4 \\
\hline Competence & $\begin{array}{c}\text { Knowledge, understanding } \\
\text { and proficiency }\end{array}$ & $\begin{array}{l}\text { Methods for } \\
\text { demonstrating } \\
\text { competence }\end{array}$ & $\begin{array}{l}\text { Criteria for } \\
\text { evaluating } \\
\text { competence }\end{array}$ \\
\hline $\begin{array}{l}\text { Plan and conduct a } \\
\text { passage and determine } \\
\text { position }\end{array}$ & $\begin{array}{l}\text { Celestial navigation } \\
\text { Ability to use celestial bodies } \\
\text { to determine the ship's } \\
\text { position } \\
\text { Terrestrial and coastal } \\
\text { navigation } \\
\text { Ability to determine the ship's } \\
\text { position by use of: } \\
.1 \text { landmarks } \\
.2 \text { aids to navigation, } \\
\text { including lighthouses, } \\
\text { beacons and buoys } \\
.3 \text { dead reckoning, taking in } \\
\text { account winds, tides, } \\
\text { currents and estimated } \\
\text { speed }\end{array}$ & $\begin{array}{l}\text { Examination and } \\
\text { assessment of } \\
\text { evidence obtained } \\
\text { from one or more of } \\
\text { the following: } \\
.1 \text { approved } \\
\text { in-service } \\
\text { experience } \\
.2 \text { approved } \\
\text { training ship } \\
\text { approved } \\
\text { simulator } \\
\text { training, where } \\
\text { appropriate } \\
\text { anproved, } \\
\text { equorotury } \\
\text { training } \\
\text { using chart } \\
\text { catalogues, charts, } \\
\text { nautical } \\
\text { publications, radio } \\
\text { navigational } \\
\text { warnings, sextant, } \\
\text { azimuth mimor, } \\
\text { electronic } \\
\text { navigation }\end{array}$ & $\begin{array}{l}\text { The information obtained } \\
\text { from nautical charts and } \\
\text { publications is relevant, } \\
\text { interpreted correctly } \\
\text { and properly applied. All } \\
\text { potential navigational } \\
\text { hazards are accurately } \\
\text { identified } \\
\text { The primary method of } \\
\text { fixing the ship's position } \\
\text { is the most appropriate } \\
\text { to the prevailing } \\
\text { circumstances and } \\
\text { onditions } \\
\text { he position is } \\
\text { determined within the } \\
\text { limits of acceptable } \\
\text { instrument/system } \\
\text { errors } \\
\text { The reliability of the } \\
\text { information obtained } \\
\text { from the primary method } \\
\text { of position fixing is } \\
\text { checked at appropriate } \\
\text { intervals } \\
\text { Calculations and } \\
\text { measurements of } \\
\text { navigational information } \\
\text { are accurate }\end{array}$ \\
\hline
\end{tabular}

Fig. 5 Table A-II/1 of the STCW Code (source: International Convention on Standards of Training, Certification and Watchkeeping for Seafarers (STCW) 1978 as amended in 1995/2010)

\section{Model course to demonstrate and revalidate deck officers' competences using simulators}

\subsection{IMO model courses}

In order to give assistance to those starting out using simulators in their training programmes, a number of model menus have been developed as guidance for such implementation.

IMO, through contributions and government sponsoring, has invested heavily in the further improvement of maritime training and education programmes. The well-known World Maritime University (WMU), being a prominent example, was established in 1983 under the philosophy that it would be more effective to bring the developing world to experts than sending experts to the developing world.

Once graduated from WMU, the newly trained teachers and instructors upon returning to their countries are often faced with a lack of teaching programmes and materials. For this purpose, standard menus to conduct courses in numerous maritime subjects have been developed in the form of the so-called IMO model courses (IMO 2005).

These revalidation model courses have been developed following the model course structure adopted by the International Maritime Organization (IMO). 


\subsection{Design a revalidation model course structure}

Including all competences evaluable with a simulator mentioned in the above section, we designed two model courses: one for the operational level and one for the management level.

Each model course has been designed following the main parts of IMO model courses:

- Part A. Course framework: Those who successfully complete this course should be able to demonstrate sufficient knowledge, skill and understanding of the competences (that can be evaluated using a simulator) described in Tables A-II/1 and A-II/ 2 of the STCW Code, as amended. The knowledge, skill and understanding are defined in column 2 of Tables A-II/1 and A-II/2.

- Part B. Course outline and timetable: This section presents the topics of the 43-h course in a simplified outline format. The 37 topics are organised into seven general subject areas or exercises,

- Familiarisation

- Planning a voyage (group of exercises, Nr. 1)

- Watchkeeping (group of exercises, Nr. 2)

- Manoeuvring (group of exercises, Nr. 3)

- Cargo handling for different kinds of ships (group of exercises, Nr. 4)

- Emergencies and rescue (group of exercises, Nr. 5)

- Controlling the operations of the ship and care on board (group of exercises, Nr. 6)

For evaluating the trainee, these exercises should be shorter and one exercise from each group should be selected. Moreover, a familiarisation with the simulation tools is also necessary for the trainee.

Both courses are a 43-h course allocated in the following manner (see Appendix 1). The duration allocated to each topic is presented in the course timetable of the model courses. This hour distribution has been decided after considering the results obtained in Fig. 4. The great variety with respect to the duration of $\mathrm{CoC}$ courses led us to adopt a midpoint that would be adequate for all the different countries analysed. A 7-day course is considered to be sufficient to evaluate all competences using different simulation scenarios, taking into account that students only have to refresh a knowledge they have previously acquired.

Another important point involves elaborating all supporting materials (SMs), and, finally, determining the time required for explaining and evaluating all skills/ knowledge points.

The tables of the competences evaluable in each group are included in Appendix 2.

Generally, each simulation training has a duration of $2 \mathrm{~h}$, being the first half hour as briefing and the last half hour as debriefing, with $1 \mathrm{~h}$ of simulation in between.

The timetable in Appendix 3 has been thought for doing two sessions in the mornings and one session in the afternoons during 7 days. Between both morning sessions, a break of $0.5 \mathrm{~h}$ is recommended. For example, if the first session starts at 0900 hours and finishes at 1100 hours, the second one starts at 1130 hours and finishes at 1330 hours and the third one starts at 1600 hours and finishes at 1800 hours, except for the last day (evaluation) that it finishes at 1900 hours. Otherwise, a more intensive course may be done with two sessions in the morning and two more in the afternoons 
for 5 days, adding a sixth morning for evaluating the trainees. In both cases, the course consists of 20 sessions of $2 \mathrm{~h}$ and 1 exam of $3 \mathrm{~h}$.

- Part C. Detailed teaching syllabus: The material listed in the course framework has been used to structure the detailed teaching syllabus, in particular:

- Teaching aids (indicated by A),

- Bibliography (indicated by B),

- IMO references (indicated by $\mathrm{R}$ ) and

- Textbooks (indicated by T).

In IMO courses, electronic media are indicated by E, but in this particular case, the research project developers have considered, according to the objective of this course, that it makes no sense to distinguish between electronic media and other teaching aids. Therefore, simulators, like audiovisual aids and recordings, are referred to as a teaching aid, indicated by A.

Table 2 includes, in a wider form, the knowledge/skills of one topic as an example and the teaching aids and references that are used for the operational level. The teaching aids are provided for each specific knowledge/skill, while the references are given for a whole subject area, except for watchkeeping, due to its extension.

- Part D. Evaluation and assessment: The learning objectives specified in the detailed teaching syllabus will provide a sound basis for the construction of suitable simulations/tests for evaluating trainee progress. It is also important to note that the supporting materials should be provided, and the trainee should be evaluated, before each simulator session.

- Part E. Instructor manual: The instructor manual section defines the scenario for each of the tasks, taking into account that each exercise has different parts, contents and objectives, which are the following:

- Level/exercise number

- Title

- References

- Objectives

- Prerequisites

- Briefing

- Training materials

- Initial condition of the simulator

- Student and instructor actions

- Duration and timetable

- Simulator run

- Debriefing/evaluation

An example scenario considering "Part D. Instructor manual" section is described as follows (see Fig. 6): 
Table 2 Example of detailed teaching syllabus for one topic (operational level)

\begin{tabular}{lll}
\hline Knowledge, understanding and proficiency & $\begin{array}{l}\text { Teaching } \\
\text { aid }\end{array}$ & Reference $^{\mathrm{a}}$
\end{tabular}

7. Controlling the operations $(3.0 \mathrm{~h})$

7.1. Ship stability $(2.0 \mathrm{~h})$ - topic 36

A1 A2 A4 R1 R2 R4 R5 R30 R42 R43

A/B R44 R45 R46 R47 R48

7.1.1. Working knowledge and application of stability, trim R49 R50 R51 R52 XXX T26 and stress tables, diagrams and stress-calculating equipment

T27 T28 T33 T34

7.1.2. Understanding of fundamental actions to be taken in the event of partial loss of intact buoyancy

7.1.3. Understanding of the fundamentals of watertight integrity

7.2. Ship construction $(1.0 \mathrm{~h})$ - topic 37

General knowledge of the principal structural members of a ship and the proper names for the various parts

\begin{abstract}
${ }^{\mathrm{a}}$ Textbooks and references are described in the following: $\mathrm{R} 1=$ Standards of Training, Certification and Watchkeeping for Seafarers, 1978 (STCW Convention), as amended, 2011 edition, IMO; R2=International Convention for the Safety of Life at Sea, 1974, as amended (SOLAS), consolidated edition 2009, IMO; R4= Model course 7.03 - officer in charge of a navigational watch, 1999 edition, IMO; R5=Model course 1.22: ship simulator and bridge teamwork, 2002 edition, IMO; R30=International Convention for the Prevention of Pollution from Ships, 1973/1978 (MARPOL), consolidated edition 2011, IMO; R42=International Conference on Load Lines, 1966, 2005 edition, IMO; R43A=Assembly Resolution A.760(18)—symbols related to life-saving appliances and arrangements, amended by MSC.82(70); R43B=Resolution MSC.82(70)-amendments to resolution A.760(18) on symbols related to life-saving appliances and arrangements, 1998; R44=Assembly Resolution A.921(22) — assembly resolutions superseded by the 1995 amendments to the 1978 STCW Convention; R45=International conference on special trade passenger ships agreement, 1971, 1972 edition, IMO; R46=Protocol on space requirements for special trade passenger ships, 1973 (SPACE STP 1973), IMO; R47=Athens convention relating to the carriage of passengers and their luggage by sea, 1974 (PAL 1974), IMO; R48=International convention on tonnage measurement of ships, 1969, IMO; R49=Assembly Resolution A.769(18)—procedures and arrangements for issuing GMDSS certificates to holders of non-GMDSS certificates; R50=IMO/ILO document for guidance, 1985, IMO; R51 = International Safety Management Code (ISM Code) and guidelines on implementation of the ISM Code, 2010 edition, IMO; R52=International Life-Saving Appliance (LSA Code), 2010 edition, IMO; T26= Derret, D.R.; Barrass, B. Ship stability for masters and mates, 7th edn. Oxford: Butterworth-Heinemann, 2008. ISBN 978-0080970936; T27=ISGOTT: International safety guide for oil tankers and terminals, 5th ed. revised. London: Witherby \& Co. Ltd., 2006. ISBN 978-1856092913; T28=Lavery, H.I. Shipboard operations, 2nd eds. London: Heinemann, 1990. ISBN 0-4434-91094-0; T33=Taylor, D.A. Merchant ship construction, 4th edn. London: Institute of Marine Engineers, 1998. ISBN 978-1902536002; T34=Roberts, P. Watchkeeping safety and cargo management in port. London: The Nautical Institute, 1995. ISBN 1-87007729-6
\end{abstract}

\title{
Course: COC revalidation course (operational level)
}

Title: TSS, approaching hinder junction, northeast bound during night time

Own ship: bulk carrier

Exercise Nr: operational 3.1

References: bridge watchkeeping (Nautical Institute ISBN 1870077172)

- Bridge team management (Nautical Institute ISBN 1870077660)

- Mariners handbook

- Collision regulations (COLREGS) 


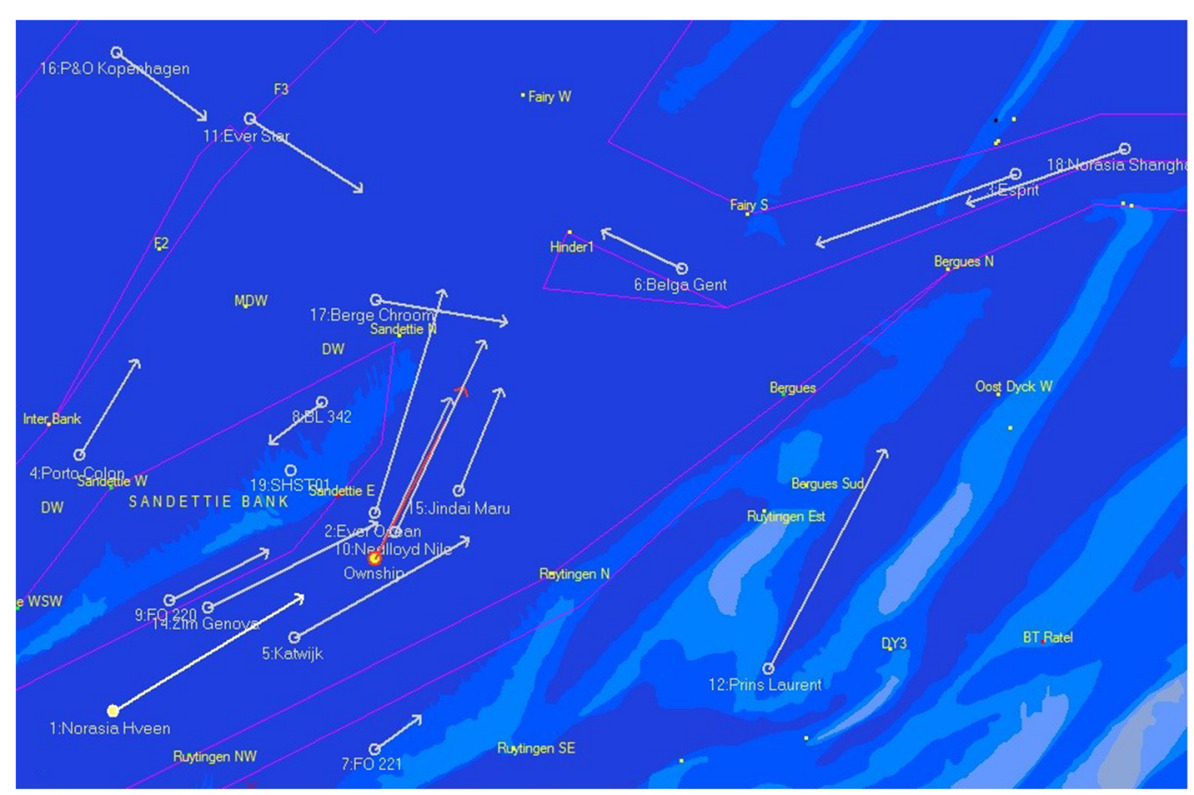

Fig. 6 Example scenario figure for operational level

- $\quad$ STCW Tables A-II/1 c1-1, c1-2, c1-3 and c1-4

Duration: briefing for $30 \mathrm{~min}$, simulator run for $60 \mathrm{~min}$ and debriefing for $30 \mathrm{~min}$ Objectives/competences: This exercise trains the student to

Plan and conduct a passage and determine position,

Maintain a safe navigational watch,

Use radar and Automatic Radar Plotting Aid (ARPA) to maintain the safety of navigation and

Use Electronic Chart Display and Information System (ECDIS) to maintain the safety of navigation.

Prerequisites:

- Basic theoretical navigational knowledge

- Knowledge of COLREGS

\section{Training materials:}

- Full mission bridge simulator (including all the navigational equipment)

- Overhead sheets and/or PowerPoint presentation

- Pilot card (ship's particulars and manoeuvring tests)

- Chart to be used (BA 323 and BA 1630)

Initial condition simulator:

- $\quad$ Type of ship: bulk carrier $(215.4 * 31.8 * 11.5)$

- Initial position: $51^{\circ} 13^{\prime} .5 \mathrm{~N}, 002^{\circ} 04^{\prime} 0.0 \mathrm{E}$. 
- Initial time: 01.00. (MET)

- Initial course: $025^{\circ}$ (ground)

- Initial speed: 15.9 knots

- Engine status: full sea speed

- i.c. gyro course: $+1.0^{\circ}$

- Tidal stream: $050^{\circ}$ at $1.5 \mathrm{kn}$

- Wind direction and speed: $\mathrm{N} 5 \mathrm{Bft}$

- Visibility: $>10 \mathrm{M}$

- Targets: see target list

- Radar: on

Target ships in exercise/position/course/speed:

Willem Barentsz $51^{\circ} 13^{\prime} 0.5 \mathrm{~N}, 002^{\circ} 04^{\prime} 0.0$ E $025^{\circ} / 15.9$

Norasia Herenveen $51^{\circ} 10^{\prime} 0 \mathrm{~N} 001^{\circ} 54^{\prime} 6$ E $059^{\circ} / 20$

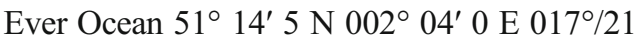

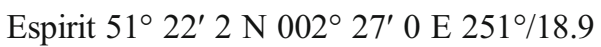

Porto Colon $51^{\circ} 15^{\prime} 8 \mathrm{~N} 001^{\circ} 53^{\prime} 4 \mathrm{E} 031^{\circ} / 10$

Katwijk $51^{\circ} 11^{\prime} 7 \mathrm{~N} 002^{\circ} 01^{\prime} 1 \mathrm{E} 060^{\circ} / 18$

Belga Gent $51^{\circ} 20^{\prime} 0 \mathrm{~N} 002^{\circ} 15^{\prime} 0$ E $295^{\circ} / 8$

FO 221 (fishing vessel) $51^{\circ} 09^{\prime} 2 \mathrm{~N} 002^{\circ} 04^{\prime} 0 \mathrm{E} 053^{\circ} / 5$

BL 342 (fishing vessel) $51^{\circ} 17^{\prime} 0 \mathrm{~N} 002^{\circ} 02^{\prime} 2$ E $233^{\circ} / 4$

FO 220 (fishing vessel) $51^{\circ} 09^{\prime} 2 \mathrm{~N} 002^{\circ} 04^{\prime} 0$ E $063^{\circ} / 10$

Nedlloyd Nile $51^{\circ} 14^{\prime} 1 \mathrm{~N} 002^{\circ} 04^{\prime} 7$ E $025^{\circ} / 19$

Ever Star $51^{\circ} 23^{\prime} 4 \mathrm{~N} 001^{\circ} 59^{\prime} 5 \mathrm{E} 123^{\circ} / 12$

Prins Laurant $51^{\circ} 11^{\prime} 0 \mathrm{~N} 002^{\circ} 18^{\prime} 1 \mathrm{E} 028^{\circ} / 22.5$

Zim Genova $51^{\circ} 12^{\prime} 4 \mathrm{~N} 001^{\circ} 58^{\prime} 0$ E $063^{\circ} / 17$

Jindai Maru $51^{\circ} 15^{\prime} 0 \mathrm{~N} 002^{\circ} 07^{\prime} 0$ E $022^{\circ} / 10$

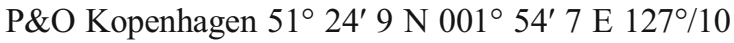

Berge Chroom $51^{\circ} 19^{\prime} 3$ N 002 $04^{\prime} 0$ E $100^{\circ} / 12$

Norasia Shanghai $51^{\circ} 22^{\prime} 7 \mathrm{~N} 002^{\circ} 30^{\prime} 9$ E $251^{\circ} / 15$

Briefing:

- Answering questions about previous exercise

- Determining the ship's position by radar, GPS, DR or sight

- Knowledge of and ability to use the nautical chart, tide tables, sailing directions and ship's routeing information

- Ability to use equipment, such as echo sounders, and apply the information correctly

- Knowledge of the principles of magnetic and gyro-compasses

- Interpretation of meteorological aspects

- Knowledge of steering control systems, operational procedures and changeover from manual to automatic control

- Knowledge of the International Regulations for Preventing Collisions at Sea

- Principals of keeping a navigational watch

- Use of routeing vessels in accordance with the general provisions of ship's routeing 
- Information from navigational equipment for maintaining a safe watch

- Use of reporting in accordance with ship reporting systems and VTS procedures

- Knowledge of blind pilotage techniques

- Knowledge of bridge resource management principles

- Knowledge of fundamentals of radar and automatic radar plotting aids

- Ability to operate and to interpret and analyse information obtained from radar/ ARPA

- Knowledge of the capability and limitations of ECDIS operations

\section{Student action:}

- Attending lecture

- Preparing sailing plan in briefing

- Monitoring and understanding the instrument reaction on the sailing ship

- Acquiring targets visually and automatically, determining the risk of collision by bearing and reacting according to COLREGS

- Taking visual and radar bearings to determine ship positions

- Acquiring and process GPS positions

\section{Instructor action:}

- Pointing out the traffic before handing over the watch

- Monitoring and observing students and ascertaining if objectives are met

- Monitoring conversations in relation to the later explained SMCP

- Stays on bridge when requested by students

- Dealing with all targets according to COLREGS

\section{Debriefing:}

- Reiterating objectives and check if they are met

- Pointing out positive actions

- Starting a discussion by means of peer review

- Playing back the exercise and discussing ship's movements

- Summarising students' actions and conclusions

- Discussing points for improvement

- Checking if positions are properly noted in the chart(s)

Evaluation: Check if the students are capable of sailing the ship and have a clear understanding of basic navigation.

\section{Conclusions}

A simulator is a tool used in a learning process so the requirement to measure its effectiveness on the attainment of a learning objective is as valid as with any other tools. However, in the case of assessment of simulation training, the developments have been limited. This can be seen as partly due to the 
complexity of the training exercises, partly due to the difficulty of agreeing on acceptable standards.

From the results obtained in Section 3, the conclusion can be drawn that the majority of countries started implementation of $\mathrm{CoC}$ revalidation programmes for the training of maritime officers using simulators. However, answers concerning how this implementation is carried out vary considerably. Therefore, the development of simulation model courses (at operational and management levels) for revalidation of $\mathrm{CoC}$ will provide the required education level and homogenise the approaches of different countries concerning revalidation programmes in accordance with the provisions of the STCW Code for existing seafarers who need to upgrade their professional maritime knowledge. These courses will also provide training using simulation material.

These courses provide a guide for all maritime training institutes and government requirements for the renewing of the professional certificate for officers in charge of navigation, according to STCW requirements, as revised by the 2010 Manila Amendments, specifically where these apply to Table A-II/1 and A-II/2, knowledge, skill and understanding of all competences that may be assessed by simulation.

\section{Limitations and further research}

This course is not the entire programme for revalidating the professional certificate, but it is the part, which may be assessed by means of simulation. Therefore, it should be understood that this is a generic course which requires a complementary structure for other competences described in Tables A-II/1 and A-II/2 of the STCW Code that cannot be assessed by simulation. Therefore, it is assumed that trainees undertaking this course have accomplished some additional instruction in topics such as terrestrial navigation, have at least some familiarisation with visual navigation, have accomplished a period of supervised bridge watchkeeping duties and have prior completion of basic radar/ARPA (MC 1.07).

On the other hand, the model courses presented only consider the deck officer discipline (deck department) because of the limited time span allocated to the research project. However, it would also be interesting to develop another model course for the engine officer discipline.

Finally, an important consideration is that the course is only applicable for the revalidation purpose if the State Maritime Administration recognises and approves this method in the revalidation process according to their prevailing procedures.

\footnotetext{
Acknowledgements This paper presents the main results of the IAMU Research Project entitled "Simulation-based model course to demonstrate seafarers' competence for deck officers discipline", relevant for maritime and education training and simulation. The material and data in this publication have been obtained through the support of the International Association of Maritime Universities (IAMU) and the Nippon Foundation in Japan.
} 


\section{Appendix 1}

Table 3 Distribution of the total number of hours of the revalidation model course

\begin{tabular}{lcc}
\hline & $\begin{array}{l}\text { Operation-level revalidation } \\
\text { model course }(\mathrm{h})\end{array}$ & $\begin{array}{l}\text { Management-level revalidation } \\
\text { model course (h) }\end{array}$ \\
\hline Familiarisation with simulators & 2.0 & 2.0 \\
Briefings, debriefings and no-simulation & 16.0 & 19.5 \\
$\quad$ explanations & 22.0 & 18.5 \\
Simulation trainings & 2.0 & 2.0 \\
Evaluation in simulators & 1.0 & 1.0 \\
Evaluation with theoretical exam & & \\
\hline
\end{tabular}

\section{Appendix 2}

Table 4 Main structure of the courses considering competences to be evaluated

Exercise Competences for the operational level ${ }^{\mathrm{a}} \quad$\begin{tabular}{l} 
Competences for the management $_{\text {level }^{\mathrm{b}}}$ \\
\hline
\end{tabular}

1. Familiarisation

2. Planning a voyage Competence 1.b: Terrestrial and coastal navigation: thorough knowledge of and ability to use nautical charts, such as sailing directions, tide tables, notices to mariners, radio navigational warnings and ship's routeing information. SM and NAV or NAV/RAD

Competence 2.c: The use of routeing in accordance with the General Provisions on Ship's Routeing. SM

\section{Watchkeeping}

Competence 1. Celestial navigation; terrestrial and coastal navigation; electronic systems of position fixing and navigation; echo sounders; compass (magnetic and gyro); steering control system; meteorology. $\mathrm{SM}$ and NAV or NAV/RAD

Competence 2. Thorough knowledge of the content of the International Regulations for Preventing Collisions at Sea, 1972, as amended; thorough knowledge of the content of the International Regulations for Preventing Collisions at Sea, 1972,

\section{Competence 12: Plan a voyage and conduct navigation. SM and NAV with ECDIS application and VTS}

Competence 18: Maintain the safety of navigation through the use of ECDIS and associated navigations system to assist in-command deci sion-making. NAV/RAD with ECDIS application

Competence 13: Determine position and the accuracy of resultant position fixed by any means. SM and NAV with ECDIS application

Competence 14: Determine and allow for compass errors. SM and NAV 
Table 4 (continued)

Exercise Competences for the operational level ${ }^{\mathrm{a}} \quad$\begin{tabular}{l} 
Competences for the management $_{\text {level }^{\mathrm{b}}}$ \\
\hline
\end{tabular}

as amended; the use of information from navigational equipment for maintaining a safe navigational watch; knowledge of blind pilotage techniques; the use of reporting of accordance with the General Principles for Ship Reporting Systems and the VTS procedures; knowledge of bridge resource management principles. SM and NAV, NAV/RAD, COM and VTS

Competence 3: Knowledge of the fundamentals of radar and automatic radar plotting aids; ability to operate and to interpret and analyse information obtained from radar; principal types of ARPA, their display characteristics, performance standards and the dangers of over-reliance on ARPA; ability to operate, interpret and analyse information obtained from ARPA. SM and NAV or NAV/RAD with ARPA application

Competence 4: Knowledge of the capability and limitations of ECDIS operations; proficiency in operation, interpretation and analysis of information obtained from ECDIS. SM and NAV or NAV/RAD with ECDIS application

\section{Manoeuvring}

\section{Cargo handling}

Competence 8: The effect of deadweight, draught, trim, speed and under-keel clearance on turning circles and stopping distances; the effects of wind and current on ship handling; manoeuvres and procedures for rescuing a person overboard; squat, shallow water and similar effects; proper procedures for anchoring and mooring. SM and NAV

Competence 9: Knowledge of the effect of cargo, including heavy lifts, on the seaworthiness and stability of the ship; knowledge of safe handling, stowage and securing of cargoes, including dangerous cargoes, hazardous and harmful cargoes and their effect on the safety of life and the ship; ability to establish and maintain effective
Competence 16: Establish watchkeeping arrangements and procedure. SM and NAV

Competence 17: Maintain safe navigation through the use of information from navigation equipment and systems to assist in-command decision-making. SM and NAV/RAD with ARPA application and COM

Competence 19: Manoeuvre and handle a ship in all conditions. SM and NAV, COM, SHIP and VTS

Competence 20: Operate remote controls of propulsion plant and engineering systems and services. SM and SHIP, CAR and BAL

Competence 21: Plan and ensure safe loading, stowage, securing, care during the voyage and unloading of cargoes. SM and SHIP, CAR, BAL and COM 
Table 4 (continued)

Exercise Competences for the operational level ${ }^{\mathrm{a}} \quad$\begin{tabular}{l} 
Competences for the management $_{\text {level }^{\mathrm{b}}}$ \\
\hline
\end{tabular}

communications during loading and unloading. SM and CAR, CRA and $\mathrm{COM}$

Competence 10: Inspect and report defects and damage to cargo spaces, hatch covers and ballast tanks. It depends on the simulator, with SM during the briefing

\section{Emergencies and rescue}

7. Controlling the operations
Competence 5: Emergency procedures. SM and SPI, CAR and/or BAL where appropriate and SAR

Competence 6: Search and rescue; knowledge of the contents of the International Aeronautical and Maritime Search and Rescue (IAMSAR) manual. SAR and COM where appropriate

Competence 7: Visual signalling. SM and COM where appropriate

Competence 11: Ship stability; ship construction. SM, $\mathrm{CAR}$ and $\mathrm{BAL}$
Competence 22: Assess reported defects and damage to cargo spaces, hatch covers and ballast tanks and take appropriate action. SM and a simulation depending on the simulator

Competence 23: Carriage of dangerous goods. SM and a simulation depending on the simulator

Competence 15: Coordinate search and rescue operations. SM and NAV, SAR and COM

Competence 24: Control trim, stability and stress. SM and $\mathrm{CAR}$ and BAL

Competence 25: Monitor and control compliance with legislative requirements and measures to ensure safety of life at sea, security and the protection of the marine environment. SM

Competence 26: Use of leadership and managerial skill. SM with any simulator

\footnotetext{
SM support material

${ }^{a}$ Main structure of the course considering competences to be evaluated in the operational level and simulation type of SM to be used

${ }^{\mathrm{b}}$ Main structure of the course considering competences to be evaluated in the management level and simulation type of SM to be used
} 


\section{Appendix 3}

Table 5 Example of course timetable for operational level

$\begin{aligned} & \text { Day/ } \\ & \text { period }\end{aligned}$
1st period $(2.0 \mathrm{~h}) \quad$ 2nd period $(2.0 \mathrm{~h}) \quad$ 3rd period $(2.0 \mathrm{~h})$

Day 1 1. Knowledge of the fundamentals and limitations of the simulators used in the course $(0.5 \mathrm{~h}) \mathrm{S}$

2. Ability to operate and to interpret and analyse information obtained from simulators $(1.5 \mathrm{~h}) \mathrm{S}$

Day 2 12. Thorough knowledge of the content of the International Regulations for Preventing Collisions at Sea, 1972, as amended (2.0 h) NS

Day 3 6. Terrestrial and costal navigation $(1.5 \mathrm{~h}) \mathrm{S}$, combined

16. The use of reporting of accordance with the General Principles for Ship Reporting Systems and the VTS procedures $(0.5 \mathrm{~h}) \mathrm{S}$

Day 4 22. Knowledge of the capability and limitations of ECDIS operations $(0.5 \mathrm{~h}) \mathrm{NS}$ (briefing)

23. Proficiency in operation, interpretation and analysis of information obtained from ECDIS (1.5 h) S
3. Thorough knowledge of and ability to use nautical charts, such as sailing directions, tide tables, navigational warnings and ship's routeing information (0.5 h) S and (1 h) NS combined

4. The use of routeing in accordance with the General Provisions on Ship's Routeing (0.5 h) NS

18. Knowledge of the fundamentals of radar and automatic radar plotting aids (0.5 h) NS (briefing)

19. Ability to operate and to interpret and analyse information obtained from radar $(1.0 \mathrm{~h}) \mathrm{S}$

12. Thorough knowledge of the content of the International Regulations for Preventing Collisions at Sea, 1972, as amended (0.5 h) NS (debriefing)

11. Meteorology $(0.5 \mathrm{~h})$ : weather systems, reporting procedures and recording systems NS (briefing)

15. Knowledge of blind pilotage techniques $(1.0 \mathrm{~h}) \mathrm{S}$, combined

11. Meteorology $(0.5$ h) S notices to mariners, radio

7. Electronic system of position fixing and navigation $(0.5 \mathrm{~h}) \mathrm{S}$

8. Echo-sounders $(0.5 \mathrm{~h}) \mathrm{S}$

9. Compass (magnetic and gyro) (0.5 h) NS (briefing)

10. Steering control system (0.5 h) S

20. Principal types of ARPA, their display characteristics, performance standards and the dangers of over-reliance on ARPA (0.5 h) NS (briefing)

21. Ability to operate, interpret and analyse information obtained from ARPA $(1.0 \mathrm{~h}) \mathrm{S}$

6. Terrestrial and costal navigation: dead reckoning (0.5 h) NS (debriefing)

13. Thorough knowledge of the principles to be observed in keeping a navigational watch (0.5) NS (briefing)

14. The use of information from navigational equipment for maintaining a safe navigational watch $(0.5 \mathrm{~h}) \mathrm{S}$, combined

11. Meteorology $(0.5$ h) S

17. Knowledge of bridge resource management principles $(0.5 \mathrm{~h}) \mathrm{NS}$ (debriefing)

23. Proficiency in operation, interpretation and analysis of information obtained from ECDIS (1.0 h) S, combined 11. Meteorology $(1.0$ h) S
5. Celestial navigation (2.0 h) NS 
Table 5 (continued)

\begin{tabular}{l}
$\begin{array}{l}\text { Day/ 1st period }(2.0 \mathrm{~h}) \\
\text { period }\end{array}$ \\
\hline
\end{tabular}

Day 5 24. Effect of deadweight, draught, trim, speed and under-keel clearance on turning circles and stopping distances (0.5 h) S

25. Effects of wind and current on ship handling $(0.5 \mathrm{~h}) \mathrm{S}$

26. Manoeuvres and procedures for rescuing a person overboard (1.0 h) S

Day 6 29. Knowledge of the effect of cargo, including heavy lifts, on the seaworthiness and stability of the ship $(0.5 \mathrm{~h}) \mathrm{NS}$ (briefing)

30. Knowledge of safe handling, stowage and securing of cargoes, including dangerous cargoes, hazardous and harmful cargoes and their effect on the safety of life and the ship (1.0 h) S

31. Ability to establish and maintain effective communications during loading and unloading (0.5 h)

NS (debriefing)

Day 7 35. Visual signalling (1.0 h) S

37. Ship construction (1.0 h) NS
27. Squat, shallow water and similar effects (0.5 h) S

28. Proper procedures for anchoring and mooring (1.5 h) S

29. Knowledge of the effect of cargo, including heavy lifts, on the seaworthiness and stability of the ship (1.0 h) NS

32. Inspect and report defects and damage to cargo spaces, hatch covers and ballast tanks (1.0 h) NS
29. Knowledge of the effect of cargo, including heavy lifts, on the seaworthiness and stability of the ship (0.5 h) NS (briefing)

30. Knowledge of safe handling, stowage and securing of cargoes, including dangerous cargoes, hazardous and harmful cargoes and their effect on the safety of life and the ship (1.0 h) S

29. Knowledge of the effect of cargo, including heavy lifts, on the seaworthiness and stability of the ship $(0.5 \mathrm{~h}) \mathrm{NS}$ (debriefing)

33. Emergency procedures ( 0.5 h) NS (briefing)

33. Emergency procedures ( 0.5 h) S

34. Search and rescue: knowledge of the contents of the International Aeronautical and Maritime Search and Rescue (IAMSAR) Manual $(1.0$ h) $\mathrm{S}$

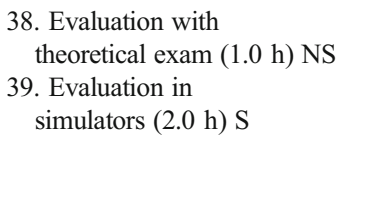

\section{References}

Barahona C, Hernández JL (1999) How the revised STCW 95 affects English language training. D. L. Newman \& M. Van Campenhoudt (Eds.) Maritime terminology: issues in communication and translation. Proceedings of the First International Conference on Maritime Terminology. Brussels: Éditions du Hazard, 214-227 
Bjorklund R, Rodahl K, Robertson BJ, Wohni B, Otherhals O, Overas P, Vespestad J, Midtgard A, (1987) Effects of maritime simulator training on performance. MARSIM 1987, Trondheim, Norway

Boer JPA (1991) Het gebruik van simulatoren voor opleiding en training: bepalende factoren voor de waarde van een simulator als leermiddel. (in Dutch), TNO-IZF, Soesterberg, Netherlands

Cross SJ (1993) An evaluation tool for simulator training. MARSIM 1993, St. John's, Canada

Cross SJ (1996) Methodology for bridge simulators skills assessment. MARSIM 1996, Copenhagen, Denmark

Daggett L (1994) Validation: the Ideal and the real; recent experiences, validation workshop. 21st Annual IMSF Meeting, Horten, Norway

Universitat Politècnica de Catalunya UPC (2014) Model course to demonstrate and revalidate decks officers' competences by using simulators. IAMU 2103 Research Project, International Association of Maritime Universities. ISBN 978-4-907408-05-3

DGSM, TNO/MSR et al. (1994) Simulator time and its seatime equivalence. Rijswijk, The Netherlands

DNV, Det Norske Veritas (1996). Rules for classification of maritime simulator centres. DNV, Høvik, Norway

Dubin F, Olshtain E (1986) Course design. Developing programs and materials for language learning. Cambridge: Cambridge University Press. http://iamu-edu.org/moodle/. Accessed November 2014

IMO ISWG (1994). STCW 26/Inf. 7. Sub-Committee STCW, submitted by Consultants/ISWG, IMO

IMO (1996) Assessment testing in a full mission bridge simulator. STW28/INF14, IMO, London, UK

IMO (2005) IMO model courses. IMO, London, UK

IMO STCW (2011) International Convention on Standards of Training, Certification and Watchkeeping for Seafarers, (STCW) 1978, as amended in 1995/2010, International Maritime Organisation, London, UK

IMSF CWG (1994) Draft classification system. Classification Working Group. St. John's, Canada

INSLC (1990) Recommended specifications for radar and navigation simulators. International Navigation Simulator Lecturers Conference, 1990

Kayten PJ, King TA, Korosh WM, Miller WC, Kaufman EJ, Williams KE (1982) Assessment of simulator based training for the enhancement of cadet watch officer performance. Caorf research study, 15-8110-02. National Maritime Research Center, Kings Point, New York, USA

McCallum MC (1996) Criterion based assessment of marine simulator operator performance. Conference on Marine Simulation, Alexandria, Egypt

MSA (1995) The effectiveness and practical application of simulators as tools for training and examining seafarers. MSA, Southampton, UK

Muirhead PMP (1988) The validation or marine simulator training. 5th INSLC, Launceston, Australia

Rowntree D (1987) Assessing students: how shall we know them. Kogan Page, London, pp 81-167

Tonsberg Maritime College et al. (1987) Report on development project sea duty on simulator. Tonsberg, Norway 